\title{
SCALE MODEL TESTS OF A FISHING VESSEL IN ROLL MOTION PARAMETRIC RESONANCE
}

\author{
NELSON A. PEREZ M. \\ Instituto de Ciencias Navales y Marítimas, M.Sc, nperez@uach.cl, \\ Universidad Austral de Chile \\ CARLOS F. O. SANGUINETTI \\ Instituto de Ciencias Navales y Marítimas, M.Sc, csanguin@uach.cl, \\ Universidad Austral de Chile
}

\begin{abstract}
This paper presents a description and some experimental results concerning the problem of parametric destabilization and roll motion resonant oscillation of ship moving in longitudinal encountering waves. This induced roll motion of a ship is of interest since it appears when moving in longitudinal waves, despite the fact that there is not any other oblique wave component to directly excite the transverse oscillation and the crew is not waiting anything like that in such a short time. The experiments were carried out on a reduced scale model of a small fishing vessel tested at the Naval Hydrodynamic Laboratory, Austral University of Chile*. The results show how those longitudinal encountering waves can develop big roll motion angles in a short time.
\end{abstract}

* Institute of Naval and Maritime Sciences, Faculty of Engineering Sciences, Austral University of Chile, Valdivia, Chile.

Keywords - Stability, in wave, off ship, parametric resonance.

\section{INTRODUCTION}

Ships of smaller dimensions in general and small fishing vessels in particular, are crafts greatly exposed to dangerous situations in waves.

The excessive motions of ships are a complicated problem and may be produced by many different factors.

Predictions are not always a simple problem, in general involve complex non-linear couplings in six degrees of freedom, and some simplifications must be considered in the mathematical models. However, since ship motion is rather complex, it can not be completely treated by analytical means alone, therefore scale model experimentation are frequently carried out in order to predict ship performance.

Studies on the dynamic phenomena affecting transversal motion of ships and transversal stability, has been extensively studied over the last decades, but it still remains of high interest due to its complicated, highly non-linear character.

Several different dangerous situations for ships in waves have already been identified long time ago , having known mathematical solutions. A few of them have not any mathematical or numerical solution up to now, one of them is the development of the so called parametric transversal resonance or low cycle transversal resonance in longitudinal waves.

This parametric roll instability phenomenon is of great interest because it appears as a sudden induced transversal resonant oscillation of a ship in following or in head regular waves, so that there is not any oblique wave component to excite transversal oscillation and the crew is not waiting anything like that in such a short time.

The phenomenon is explained through the changes of the underwater volume of the vessel as it moves through the waves, with a subsequently fluctuations in the transversal restoring moments.

As it is well known, when the vessel is on the wave crest the restoring moment is generally reduced, whereas on a wave trough the restoring is increased.

This kind of instability is a situation in which, linear mathematical equations, do not show eventual transversal destabilization and the not linear one have not know solutions. Experimental results are very important and permit the understanding of the phenomenon and provide insights to the numerical method.

\section{EQUATIONS OF ROLL MOTION.}

Let us say that right handed coordinate system Cxyz is defined as in Fig 1. Surge , Sway and Heave are the translational motions, Roll, Pitch and Yaw are angular motions with respect to axes $\mathrm{x}, \mathrm{y}, \mathrm{z}$, respectively.

A mathematical model to describe, in a simple form, the non linear uncoupled roll motion can be expressed in the form :

$$
\begin{aligned}
& \left(I_{x}+A_{44}\right) \ddot{\phi}+D(\dot{\phi})+M_{r}(\phi, z, \theta, \zeta)=M_{w o} \cos (w t-\gamma) \\
& I_{x}=\text { transversal mass moment of inertia } \\
& A_{44}=\text { roll added Inertia } \\
& D=\text { roll damping moment } \\
& M_{r}=\text { roll restoring moment } \\
& M_{w o}=\text { amplitude of wave exciting moment }
\end{aligned}
$$


$\phi, \dot{\phi}, \ddot{\phi}=$ angle, angular velocity and angular acceleration of roll motion respectively.

$\mathrm{z}=$ heave motion

$\theta=$ pitch angle

$\xi=$ wave elevation

$w=$ wave encountering frequency

$\gamma=$ phase between excitation and wave

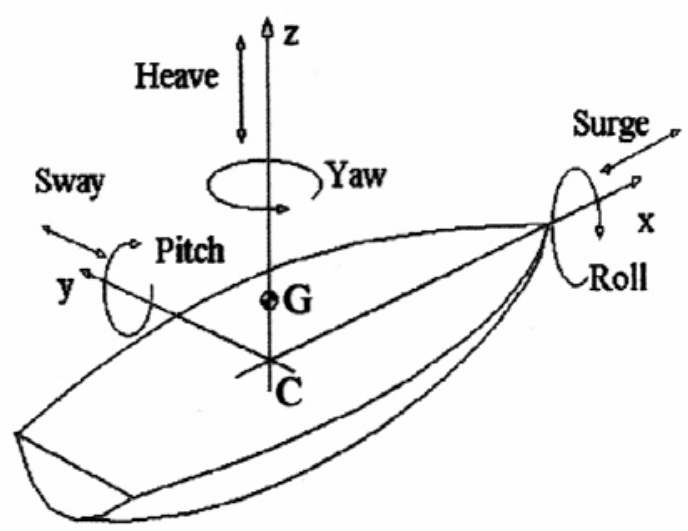

Fig. 1: Co-ordinate axis and definition of motions.

\section{Damping Moment.}

Due to the occurrence of strong viscous effects, the roll damping moment can not be satisfactorily computed in a simple linear non viscous way, so that, the total roll damping may be calculated by mean of simplified analytically or numerical method. For instance, in a semi-empirical model of roll damping moment one can assume that the total roll damping may be subdivided into several components, each one being computed separately, let us say:

$D(\dot{\phi})=B_{44} \dot{\phi}+\left[B_{44 W}+B_{44 f}+B_{44 E}+B_{44 L}+B_{44 K}\right] \dot{\phi} \mid \dot{\phi}$

Where: $B_{44} \dot{\phi}$ is the linear potential non coupled damping and $B_{44 W}, B_{44 f}, B_{44 E}, B_{44 L}, B_{44 K}$ corresponds to wave, friction, eddy, lift and bilge keel damping coefficients, respectively, even non coupled.

So, the damping moment of roll motion could be given by

$$
D(\dot{\phi})=B_{44} \dot{\phi}+B_{444}|\dot{\phi}| \dot{\phi}
$$

$B_{444}$ may be computed using different numericalempirical methods

\section{Restoring Moment.}

The roll restoring moment $M_{r}$ in waves neither can be satisfactorily computed in just a linear and non- coupled way. In general, and in a simple way it can be assumed to be given by:

$$
M_{r}(\phi, z, \theta, \zeta)=C_{44} \phi+C_{444} \phi^{3}+C_{44 z} z \phi+C_{44 \theta} \theta \phi+C_{44 \zeta} \bar{\zeta} \phi
$$

$C_{44}=\Delta \overline{G M}$, represents the basic linear non-coupled roll restoring coefficient.

$C_{44 z}, C_{44 \theta}, C_{44 \xi}$, represent time dependent variations of hull restoring characteristics due to Heave and Pitch motions and due to the amplitude of wave passage respectively.

Analytical, numerical, or numerical-empirical methods are used for the determination or estimation of all - linear and non-linear roll restoring moment component.

\section{Parametric equation.}

As the parametric resonance instability is a longitudinal waves phenomenon, then the wave exciting moment $M_{\text {wo }}=0$ in (1), that is, there is no transversal external excitation moment of roll. Dividing in equation (1) by $\left(I_{x}+A_{44}\right)$ the roll motion equation take a form given by :

$\ddot{\phi}+\left(b_{44}+b_{444}|\dot{\phi}|\right) \dot{\phi}+\left(c_{44}+c_{444} \phi^{2}+e_{o} \cos (w t+\tau)\right) \phi=0$

$e_{o}$ representing the parametric excitation contains contributions from heave and pitch motions and the wave passage effects. Equation (4) can not be solved analytically but, in order to investigate stability of the ship response one can get the "Equivalent Damped Mathieu Equation":

$$
d^{2} \varphi / d t^{2}+(\gamma) d \varphi / d t+\left[\omega_{0}^{2}+\alpha \cos (2 \pi f t)\right] \varphi=0
$$

Even though the Mathieu Equation is a linear differential equation, it can not be solved analytically in terms of standard functions. The reason is that one of the coefficients isn't constant but time-dependent. But it can be calculated numerically the areas of instability for a certain value of the constant damping, (Fig 2). In the undamped case the areas of stability are in dashed lines. According to this, an infinitesimal driving amplitude $\alpha$ destabilizes the oscillation if the parametric resonance condition is $\omega_{d} / 2 \pi f=n / 2 ; n=$ $1,2,3, \ldots$

So, the phenomenon of ship roll parametric resonance can easily start when the ship and the waves coincide in encountering frequencies we determined by .

$$
\begin{aligned}
& \omega_{e}=n \omega_{4} \quad n=1,2,3 \ldots \\
& \omega_{e}=\text { encounter frequency of exciting waves } \\
& \omega_{4}=\text { natural frequency of roll motion of ship }
\end{aligned}
$$




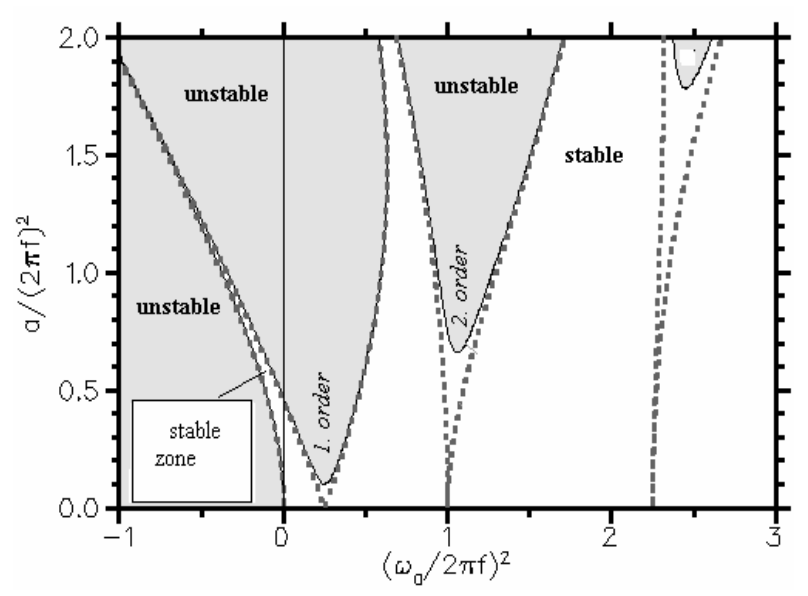

Fig 2 Stable - unstable zones in a Mathieu Equation

These frequency relations denotes areas of transversal instability generated when the ship faces with that combination of encounter frequency the passing of successive crests at middle ship and thus with a diminished restoring capacity; this enables that any transversal oscillation of small magnitude can reach successively higher roll angle with each successive oscillation, originating the so-called: "roll parametric resonance phenomenon".

It has been demonstrated that the most dangerous situation occurs when $\omega_{e}=2 \omega_{4}$ and this will be the interest tuning to test.

\section{Experimental Aspects.}

Although considerable progress has been made in analytical prediction methods, they are still not sufficiently accurate and experiments are of usefulness in order to develop or improve theoretical predictions for the phenomenon.

To be able to predict ship motions from model test, a static as well as a dynamic similitude between the ship and model must be achieved, that is, reduced scale model must be prepared , being geometrically similar, having in scale: the total weight or displacement and the longitudinal and transversal mass distribution on model must be arranged in order to reproduce the total center of gravity and radius of gyration in scale.

The experiments have been carried out at ValdiviaChile ship model Towing Tank, using a scale model of small fishing transom stern typical vessel, whose main characteristics are shown in Table 1.

Figs. 4 to 7 show some of experimental results of transversal resonant oscillation scaled to real vessel in time domain for two typical metacentric height: $0.37 \mathrm{~m}$ and $0.5 \mathrm{~m}$.
It can be noted how the transversal oscillation angle can vary from $3^{\circ}$ or $4^{\circ}$ initial to $15^{\circ}$ or $20^{\circ}$ in about 40 s or 60 s time.

\begin{tabular}{|c|c|} 
Table 1 \\
\begin{tabular}{|c|c|}
\hline Total length of ship & $25.91 \mathrm{~m}$. \\
\hline Length of water line & $22.09 \mathrm{~m}$. \\
\hline Beam & $6.86 \mathrm{~m}$. \\
\hline Depth & $2.48 \mathrm{~m}$ \\
\hline Displacement weight & $170.3 \mathrm{ton}$ \\
\hline Transversal radius of gyration & $2.06 \mathrm{~m}$. \\
\hline Longitudinal radius of gyration & $5.5 \mathrm{~m}$ \\
\hline Scale model & 30 \\
\hline
\end{tabular}
\end{tabular}

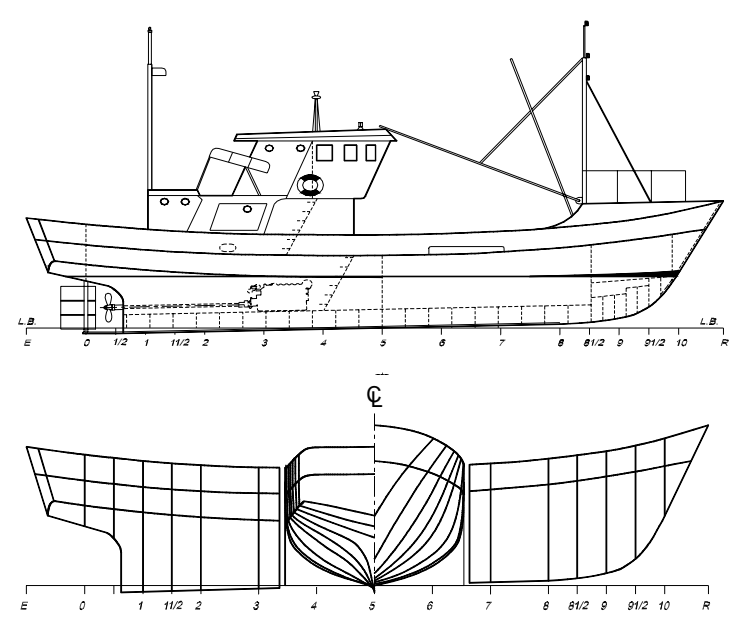

Fig 3. Fishing Vessel and body plans for scale model.

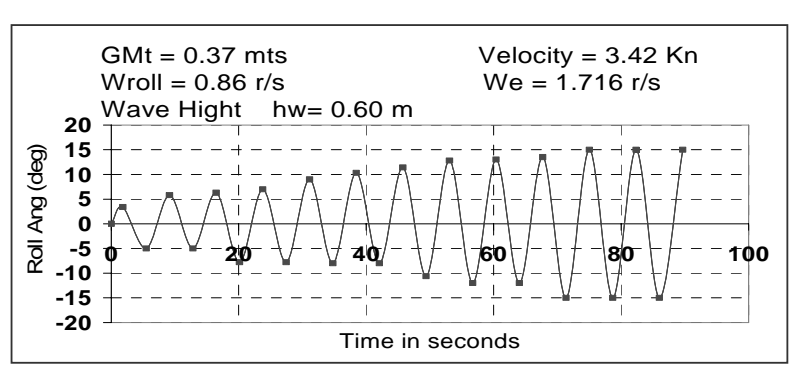

Figure 4.

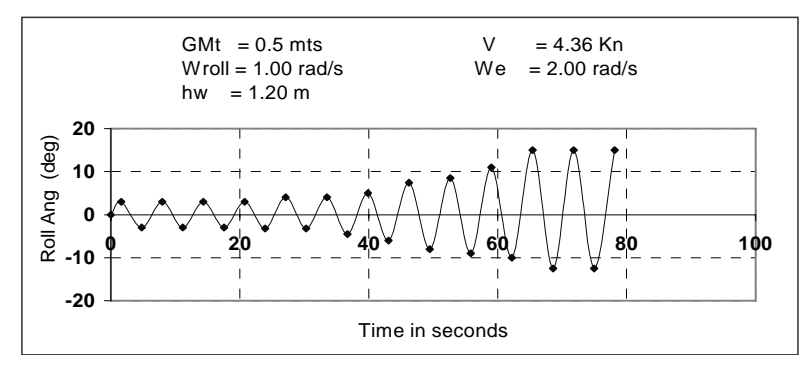

Figure 5 


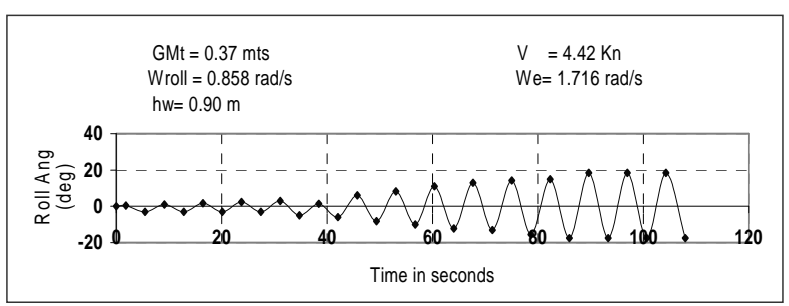

Figure 6

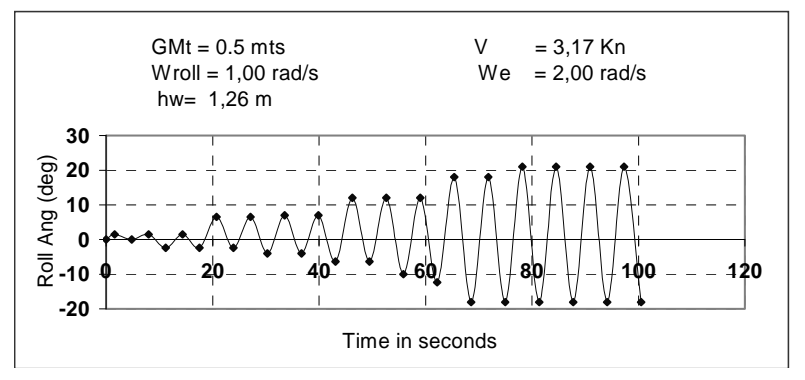

Figure 7

Figs. 8 and 9 allow show the maximum angles reached in this phenomenon in terms of speed of ship expressed by means of the Froude Number for ships as usual, $F n=V b /(L g)^{0.5}$

$V b=$ ship speed, $L=$ ship length,$g=$ gravity . Both, metacentric heights $0.37 \mathrm{~m}$. and $0.50 \mathrm{~m}$.

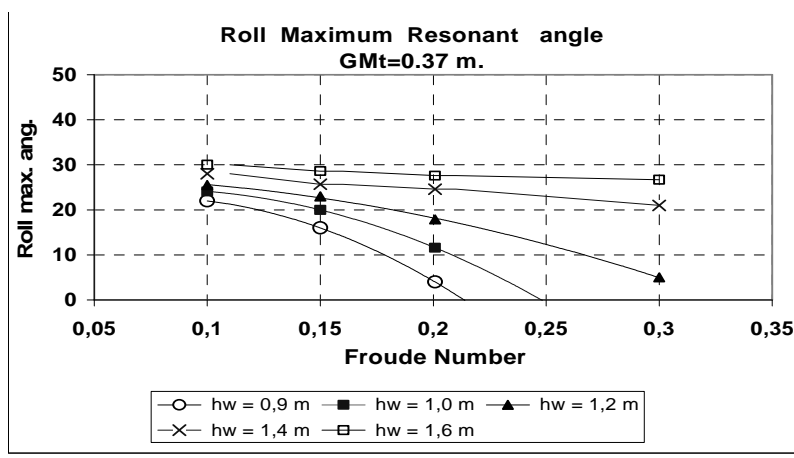

Figure 8

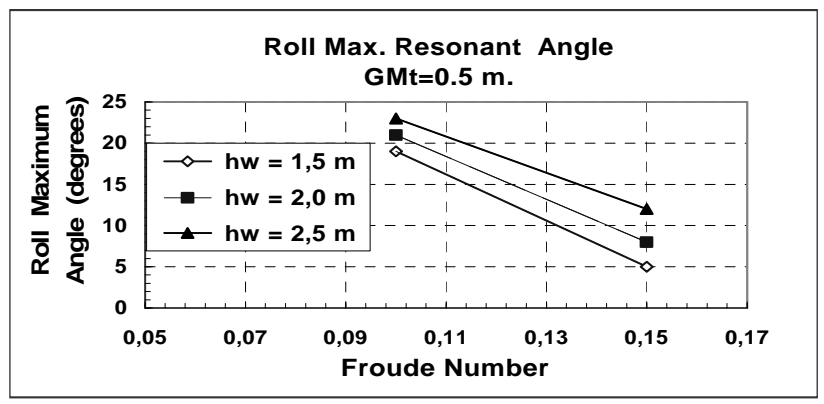

Figure 9

\section{CONCLUSIONS}

1. As can be seen, the resonant transversal parametric phenomenon, if present, can achieve great magnitude; reaching roll angles that can eventually generate other events dangerous in the operation of the ship, such as water boarding , load running, etc. with all the adverse technical implications likely to happen. So, it must be considered by designers and crews.

2. It is observed that in the majority of cases the phenomenon has a sudden development which is noticeable in time domain.

3. Notwithstanding the above, the following should be kept in mind: for the phenomenon to occur it is necessary for the waves to present a relatively regular appearance, and for the tuning described in (6) between the encounter frequency and the roll oscillation natural frequency of the ship to exist. But it is also perceived that there should exist a minimum excitation of the waves, capable of originating the phenomenon, the wave height being a good reference pattern.

4. When the height of the wave is enough to originate the phenomenon both the roll angle amplitude achieved and the time in which high roll values are reached are observed to be greatly influenced; once again wave height springs here as one of the most dangerous variables in this situation.

In higher values of Froude Number, that is, higher speed of ship, the phenomenon does not occur easily, wave heights must be greater magnitude, i.e. a necessary minimum excitation is required to originate the phenomenon, as it is shown in the unstable zones diagram in Fig.2.

5. Finally, the Metacentric Height of the ship in this case appears to influence with the consistency expected for the main static transversal stability variable, even when it should not be forgotten that the roll parametric resonance phenomenon is not one of 
normal static stability but an in-wave ship dynamics phenomenon .

\section{REFERENCES}

[1] Kerwin, J.E. "Notes on rolling in Longitudinal Waves”, International Shipbuilding Progress, Vol $2,16,1955$.

[2] Paulling, J.R. "The Transverse Stability of Ship in Longitudinal Seaway” Journal of Ship Reaserch, $\mathrm{N}^{\circ} 4,1961$.

[3] Blocki, W.; "Ship Safety in Connection with Resonance of the Roll"; International Shipbuilding Progress, No 306, 1980.

[4] Hamamoto M. et al; "Analysis on Low Cycle Resonance of Ships in irregular Astern Seas", JSNAJ, No 178, 1995.

[5] Skomedal, N.; "Parametric excitation of Roll Motion and its influence on Stability", Proceedings of $2^{\circ}$ Int. Conference on Stability of Ships and Ocean Vehicles. Tokyo, Oct. 1994.

[6] Neves M., Pérez N., Valerio L.; "Stability of small fishing vessels in longitudinal waves" , Ocean Engineering, Vol 26, No 12, Dec 1999.

[7] Neves, M. A. S., Pérez, N., Lorca, O., Rodríguez, C., Hull Design Considerations for Improved Stability of Fishing Vessels in Waves. In: Proceedings of 8th , 2003 International Conference on the Stability of Ships and Ocean Vehicles Madrid, Spain.

[8] Umeda, N., Hashimoto, H., Vassalos, D., Urano, S., Okou, K.,. Non-Linear Dynamics on Parametric Roll Resonance with Realistic Numerical Modeling. Proceedings of 8th International Conference on the Stability of Ships and Ocean Vehicles (STAB'2003), Madrid, Spain.

[9] Spanos, D. Papanikolau, A,. Numerical Simulation of a Fishing Vessel in Parametric Roll in Head Seas, $8^{\circ}$ International Workshop on Stability and operational safety of Ships, Istambul 2005, Turkey.

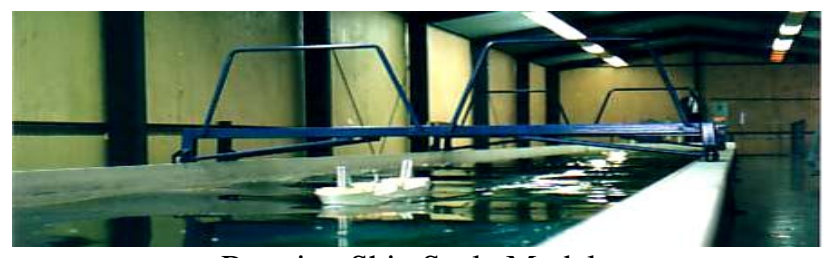

Running Ship Scale Model

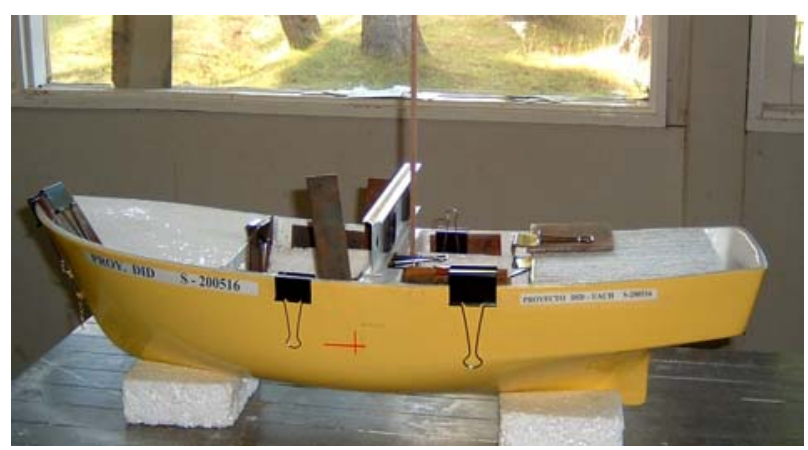

Scale model being arranged

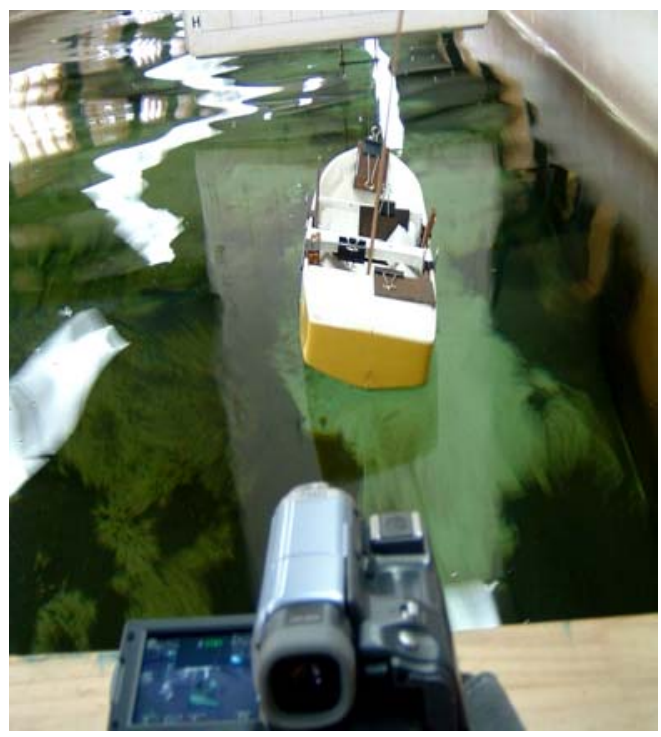

Roll Oscillation Test
APPENDIX A

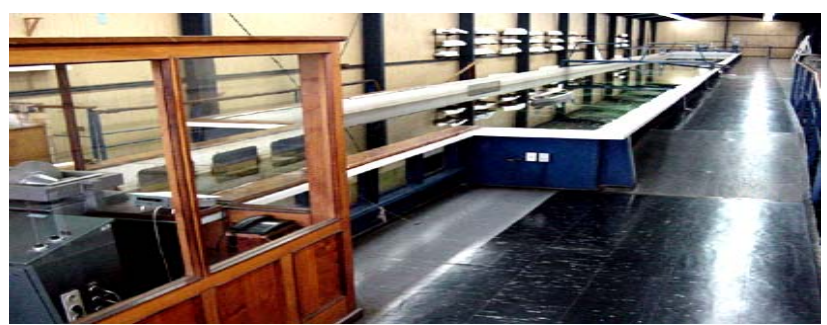

Valdivia Ship Model Towing Tank -

Hydrodynamic Lab. (Austral University of hile) 
